\title{
Функционирование неологизмов и окказионализмов из сферы информатики и интернет-коммуникации в современном украинском языке
}

\author{
The Functioning of Neologisms and Occasionalisms from the Field of Computer \\ Science and Internet Communication in Modern Ukrainian
}

Funkcjonowanie neologizmów i okazjonalizmów z dziedziny informatyki i komunikacji internetowej we współczesnym języku ukraińskim

\begin{abstract}
This paper is devoted to the analysis of term generation in the field of computer science and i-net communication using the native word-formative tools of the Ukrainian language. Particular attention is paid to the functioning of such neologisms in common usage (linguistic usus). Ukrainian electronic resources are used as a research material and verification tool. Morphemic, word-formative and comparative analysis of derivatives and the method of periphrasis allowed us to determine the reasons for the production of appropriate and inappropriate special names that can compete with English borrowings in this field.
\end{abstract}

Key words: neologism, new borrowing, neosemanticism, occasionalism

\begin{abstract}
Аннотация: Статья посвящена анализу терминотворчества в сфере информатики и интернет-коммуникации с использованием исконных словообразовательных средств украинского языка. Особое внимание уделено функционированию таких неологизмов в узусе. В качестве материала исследования и инструмента верификации используются украинские электронные ресурсы. Использование морфемного, словообразовательного и сопоставительного анализов дериватов, а также метода перифраз позволило определить причины создания удачных, способных конкурировать с английскими заимствованиями, и неудачных специальных наименований в этой сфере.
\end{abstract}

Ключевые слова: неологизм, неозаимствование, неосемантизм, окказионализм

\begin{abstract}
Abstrakt: Artykuł poświęcony jest analizie tworzenia terminów w dziedzinie informatyki i komunikacji internetowej z wykorzystaniem rodzimych narzędzi do tworzenia słów w języku ukraińskim. Szczególną uwagę poświęca się funkcjonowaniu takich neologizmów w uzusie. Jako materiał badawczy i narzędzie weryfikacyjne wykorzystywane są ukraińskie zasoby elektroniczne. Zastosowanie analizy morfologicznej, słowotwórczej i konfrontatywnej derywatów oraz metody peryfraz pozwoliło nam ustalić przyczyny tworzenia udanych i nieudanych nazw specjalnych, które mogłyby konkurować $z$ angielskimi zapożyczeniami $w$ tej dziedzinie.
\end{abstract}

Słowa kluczowe: neologizm, nowe zapożyczenie, neosemantyzm, okazjonalizm 


\section{1. Вступление}

Современные лингвистические исследования все шире используют возможности цифровых технологий для обработки языковой информации и ресурсы интернет-пространства. Новая исследовательская среда, называемая циифровой гуманитаристикой (англ. digital humanities / пол. humanistyka cyfrowa / укр. uифрова гуманітаристика), объединяет различные практики и методы гуманитарных наук и компьютерного (цифрового) инструментария: создание цифровых продуктов, т.е. представление той или иной сферы лингвистических исследований в цифровом виде, либо же использование электронных ресурсов (электронных словарей, баз данных, корпусов и т.д.). В фокусе внимания лингвистов пребывает и терминология информатики, которая осмысливает и отображает в терминах процессы сбора, хранения и передачи информации, новые средства ее распространения, а также общения между пользователями, в том числе образование новых номинаций понятий и процессов, пребывающих в постоянном развитии и обновлении (БулАховський, 2010; JóźwiKIEWICz, 2011; Клименко, 2016: 149; 2017). Формирование компьютерной терминологии, как и обновление современного лексикона в целом, происходит за счёт конкуренции различных типов новых номинаций, таких как: новообразования, т.е. новые производные (укр. новотвори), новые значения слов (неосемантизмы, укр. неосемантизми) и новые заимствования (неозаимствования, укр. неозапозичення, новозапозичення) (КАРПІловсьКА, 2008: 12).

Среди способов номинации новых терминов в украинском языке преобладают заимствования, преимущественно интернационализмы английского происхождения (браузер, драйвер, сервер, сайт, файл и др.), однако исследователи отмечают использование и собственных ресурсов языка, обращая особое внимание на роль семантического словообразования в терминосистеме, метафору и метонимию как источник формирования новых значений терминов и активизации словообразовательного потенциала терминов информатики (вікно, мережа, миша/мишка, носій, пам'ять) (Клименко, 2017: 122-183). Остается актуальной проблема образования специальной терминологии на исконно украинской почве, особенно остро возникающая при локализации программного обеспечения, переводе интерфейса программ, поиске адекватных эквивалентов терминов и т.д.

Целью предлагаемого исследования является анализ авторского образования терминов информатики средствами украинского языка, а также производных неологизмов, функционирующих вне терминосистемы: в частности, в художественной литературе и коммуникативной практике соцсетей. Особое внимание уделено окказиональному словообразованию, роли и значению окказиональных единиц в усовершенствовании украинской компьютерной терминологии, взаимодействию и конкуренции их с узуальными наименованиями.

Окказиональное словообразование, соотношение узуального и окказионального как регулярного и нерегулярного в языке довольно глубоко освещено в работах Алексея Георгиевича Лыкова, Елены Андреевны Земской, Ольги Сергеевны Захаровой. Клара Бузашшиова и Ольга Мартинцова акцентируют внимание в своих исследованиях на важном отличии неузуального (окказионального) словообразования от словообразования узуального с точки зрения соотношения нормы словообразовательной (нестандартное образование слов) и лексической (неупотребительная, нестабилизировавшаяся в языке лексика) (BuZAssyova, Martincova, 2003: 262). В польской дериватологической традиции принято определение окказионализмов как текстовых словообразовательных дериватов, системных и внесистемных, но нестабили- 
зированных относительно лексической нормы языка (CHRUŚcIŃsKA, 1978: 75; JADACKA, 2001: 38), т.е. окказионализм не входит в лексическую систему языка (BeLENTSCHIKow 2003: 249). Исследователи отмечают также, что окказиональные дериваты отличаются от общепринятых новообразований индивидуальностью и тем, что образуются не по существующим моделям, а по аналогии с отдельными словами (образцами) и формируют особенную подсистему словообразования (Янко-ТриницкАЯ, 2001: 463, 481). В энциклопедии «Українська мова» предложено следующее определение, принятое в работе:

Окказионализм - необычное, преимущественно экспрессивно окрашенное слово, образованное на базе существующего в языке слова или словосочетания, иногда с нарушением законов словообразования или языковой нормы, функционирующее только в определенном контексте, в котором оно возникло.

Пустовіт, Клименко 2004: $432^{1}$

Существенным для окказионализма признаком украинские лингвисты считают нарушение принятого образца образования слова: 1) образца когнитивной структуры номинации, 2) ономасиологической, 3) словообразовательной структуры, словообразовательной техники ее оформления (КолОї3, 2007: 3-9; КАРПІЛОвСьКА, 2008: 52-53). Привязанность окказионализма к контексту также отличает его от узуального новообразования. Обычно окказионализмы рассматривают как результат индивидуально-авторского словотворчества в художественном тексте, публицистике или в разговорной речи с целью передачи отношения автора, его оценки происходящего. Окказиональные производные в компьютерной терминологии как результат создания нейтральных единиц, называющих новые понятия с использованием национальных ресурсов, рассматриваются впервые.

\section{2. Материал}

Для поиска материала, для анализа и верификации неологизмов или окказионализмов в текстах различных стилей и подтверждения их узуальности/неузуальности в нашем исследовании использовались прежде всего электронные ресурсы, созданные украинскими лингвистами, а также словари новой лексики, тексты, в частности художественная литература для детей.

Основным источником анализируемого материала послужил сайт «Словотвір» (Словообразование, режим доступа: https://slovotvir.org.ua/). Его можно рассматривать в качестве реакции на обеспокоенность ЮНЕСКО огромными рисками для многих языков в связи с глобализацией и рекомендацию сохранить языковое разнообразие в киберпространстве с помощью перевода информации в Интернете с английского на другие языки. Авторы сайта - программисты (не лингвисты!), особенно остро ощущающие «англизацию» в своей профессиональной сфере. Этот интерактивный сайт создан с целью поиска, предложения, обсуждения и оценки исконных вариантов-наименований - заменителей новых и старых

${ }^{1}$ Оказіоналізм - незвичне, здебільшого експресивно забарвлене слово, утворене на основі наявного в мові словосполучення, іноді з порушенням законів словотворення чи норми мовної, що існує лише в певному контексті, в якому воно виникло (Пустовгт, Клименко, 2004: 432). 
заимствований. Таким образом украинские программисты пытаются возродить традицию создания терминов на исконной языковой почве. Украинские эквиваленты заимствований образованы с помощью различных способов словообразования, калькирования, в том числе и семантического, и часто являются окказиональными образованиями.

Эталоном для верификации отдельных лексем как неологизмов послужил Компьютерный морфемно-словообразовательный фонд украинского языка, созданный на базе авторитетных словарей литературного языка в начале 1980-х годов сотрудниками отдела структурно-математической лингвистики под руководством профессора Нины Федоровны Клименко (сначала в составе Института языковедения имени А.А. Потебни, а с 2011 года - Института украинского языка Национальной академии наук Украины в Киеве). Фонд под руководством профессора Евгении Анатольевны Карпиловской постоянно развивается и пополняется новыми материалами и программными средствами для работы с ним. Вторым источником верификации неологизмов стал «Грамматический словарь украинского литературного языка. Словоизменение» (Киев, 2011), созданный авторским коллективом, возглавленным Валентиной Ивановной Критской. Электронная версия этого словаря, созданная совместно с программистом Виктором Михайловичем Сорокиным, свободно доступна для работы в Интернете на лингвистическом портале лаборатории компьютерной лингвистики Института филологии Киевского национального университета имени Тараса Шевченко (режим доступа: http://www. mova.info). Дополнительным ресурсом для верификации того или иного слова как неологизма является сайт r2u (англ. Russian to Ukrainian, т.е. с русского на украинский), «Русско-украинские словари», представляющий прежде всего переводные раритетные «допогромные» (до сворачивания политики «украинизации» сталинским режимом в 1930-х годах) русско-украинские словари (17 словарей), подробнее см. (СТАРКо 2017: 86-100).

Уже упомянутый лингвистический портал mova.info представляет возможность верифицирования окказионализмов и неологизмов в тестовой версии корпуса текстов украинского языка, созданной в лаборатории компьютерной лингвистики Института филологии Киевского национального университета имени Тараса Шевченко (руководитель Наталья Петровна Дарчук). Корпус состоит из шести подкорпусов (по порядку убывания их размера: публицистических, художественных, научных, законодательных, поэтических и фольклорных) общим объемом около 100 млн. словоупотреблений (режим доступа: http://www.mova. info/corpus.aspx?11=209). Другим корпусом, предоставленным для свободного использования в интерактивном режиме, является Генеральный регионально аннотированный корпус украинского языка (ГРАК, режим доступа: uacorpus.org.) - постоянно пополняющаяся коллекция из более чем 50 тыс. текстов различных жанров на украинском языке, охватывающая период от начала XIX до начала XXI века. Особенностью этого корпуса является его региональная разметка, дающая информацию о функционировании слова в том или ином регионе Украины.

Дополнительными ресурсами для верификации окказионализмов стали: Компьютерный фонд инноваций (КФИ) в современном украинском языке, реализованный этим же научным коллективом под руководством Е.А. Карпиловской и созданный на его основе новый, идеографический тип словаря новой лексики «Активные ресурсы современной украинской номинации» (Киев, 2013; отв. ред. Е.А. КАРПиловскАя); Архивная лексическая картотека украинского языка, оцифрованная в Институте украинского языка НАН Украины благодаря поддержке Украинского культурного фонда в 2018 г. (руководитель проекта Оксана 
Николаевна Тищенко) и функционирующая онлайн в тестовом режиме (режим доступа: http://mova.cf).

\section{3. Анализ материала}

На сайте «Словотвір» представлены новые заимствования различных тематических групп, предложенные как возможность для словотворчества и поиска украинских эквивалентов. Среди них группы «ІТ» (639 слов), «Технології» (805 слов), «Медіа» (317 слов), включающие и компьютерную интернациональную терминологию: баг, блок, браузер, демоверсія, дисплей, драйвер, інтерфейс, картридж, клавіатура, конектинг, куки, монітор, принтер, процесор, сайт, сервер, сканер, спам, файл и др.

Описывая процессы развития терминосистемы информатики, Н.Ф. Клименко отметила ее бурное развитие в период глобализации, выражающееся в возникновении и заимствовании нових терминов, образовании фонда интернационализмов, формировании групп семантических калек (Клименко, 2017: 122). Большинство анализированных заимствований этой терминосистемы имеют небольшой словообразовательный потенциал (вірус - 6 производных, процесор - 5 производных) либо не имеют его вовсе (блютуз, софт) (Клименко, 2017: 158-159). Выход терминов за границы терминосистемы часто связан с процессами их метафоризации, переосмысления и словообразовательной активности в новом значении. Например, в разговорном стиле, в художественных текстах функционирует деминутив вірусочок (ЕСАулов, 2013b: 10), в значении 'вредного файла для операционной системы компьютера', но с оценочными признаками не только 'вредный, опасный', но и 'смешной, остроумный' и даже 'маленький, милый'.

Исследуемая лексика находится на периферии терминосистемы информатики или вне терминосистемы, поскольку в большинстве состоит из авторских новообразований, являющихся претендентами на статус термина вместо заимствований. Это словотворчество заинтересованных пользователей сайта «Словотвір», преимущественно программистов. За типом новых номинаций анализируемую лексику предлагается классифицировать на: 1) неосемантизмы (общеупотребительная лексика, которая вследствие метонимии, расширения или сужения значения может быть использована в качестве термина; сюда же относится лексика из других терминогрупп, которая способна «мигрировать» в сферу компьютерной терминологии); 2) новообразования; 3) окказионализмы. Из общего количества около 1750 слов, список терминов, составивший ядро для словотворчества, составил около сотни слов, включающий лексику всех трех групп.

\section{4. Неосемантизмы}

Межстилевая миграция терминов вследствие метафоризации чаще касается заимствований, например, вірус, шлюз (Клименко, 2017: 152). На сайте автор Юрко Зеленый предлагает заменить файл (англ. file - 'шухляда, папка'), обозначающий именованную область данных на носителе информации, сельскохозяйственным термином сніп (рус. сноп) либо другими вариантами: зшиток, жмут на основании внешней похожести (как и вікно, мишка) - все 
предложенные слова обозначают целостную и одновременно собирательную единицу чеголибо (стеблей, бумажек, также, как и совокупность данных). Но в данное время термин файл уже прочно закрепился в терминосистеме, образует словообразовательное гнездо, и потому предложенные варианты не могут составить ему конкуренцию. Верификация функционирования предложенных слов в значении файла в текстовом материале корпусов не обнаружила примеров употребления.

Удачным вариантом можно считать неосемантизм реn'яшки вместо куки (англ. cookies 'пирожное, печенье'). Неосемантизм реп'яшки (репейнички - семена репейника, цепляющиеся за любые негладкие поверхности) в значении 'информация в виде текстовых или бинарных данных, полученных от веб-сайта на веб-сервере, сохраняющаяся у клиента’ образован на основе функциональной метафоры: «Когда заходишь на сайт, они (репейники) к тебе цепляются, и потом они постоянно с тобой - отсылаются туда-сюда в каждом запросе» (объяснение пользователя) активизировался в узусе именно в этом значениии, что подтверждают примеры и статистические данные поиска в Гугл, и даже прижилось в украинской компьютерной терминологии.

Украинское слово равлик (рус. улитка) в новом значении 'символ в сетевых сервисах для отделения имени пользователя от названия домена' используется как неосемантизм на основе метафорического переноса внешнего признака, подобия вместо скалькированного с русского образца собака для обозначения @ (англ. at the rate) (действительно, знак @ (коммерческое at) похож на улитку) и неосемантизм равлик становится более популярным. Параллельно (с разной активностью) функционируют и другие его названия: собака/собачка, вухо/вушко, песик, мушля, образованные таким же способом. Ассоциативная метафора лежит в основе названий @ и в других славянских языках (рус. собака, пол. таłра, белор. сабака, малпа, слімак).

Удачным вариантом можно назвать активизированную лексему речене́ць вместо дедлайн (англ. deadline). Слово реченець в значении 'конечный, окончательный срок, термин' как нейтральная единица литературного языка зафиксировано в академических словарях 1920-30-х годов (что подтвержает поиск на сайте $\mathrm{r} 2 \mathrm{u}$ ) и текстах (326 найденных примеров в корпусе ГРАК).

\section{5. Новообразования}

Авторское новообразование вподоба́йка вместо лайк (англ. like - укр. 'до вподоби', рус. 'по душе (сердцу), нравится') в значении условного выражения одобрения, предложенное на сайте «Словотвір» в 2014 году, сегодня присутствует в одном примере корпуса ГРАК и в более чем 40000 результатов поиска в Гугл (в электронных СМИ, в соцсетях и на форумах).

Ярким примером возможности вхождения в компьтерную терминологию удачного новообразования является застосунок (англ. application, app, рус. приложение) - пользовательская компьютерная программа, позволяющая решать конкретные прикладные задачи пользователя. В украинских специализированных текстах его ошибочно переводили как прикладна програма, додаток. Русский термин приложение является омонимичным и переводится на украинский и как додаток, и как застосування. Но, учитывая значение английского термина, правильным будет перевод застосовна програма или застосунок. В последнее время именно этот вариант использует Microsoft. Корпус ГРАК насчитыват 149 примеров, преимущественно 
в значении термина. На сайте $\mathrm{r} 2 \mathrm{u}$ термин зафиксирован в «Російсько-українському народному словнику» с упреждением «потребує додаткового обговорення».

Среди других предложенных новообразований можно назвать зламник вместо хакер (англ. to hack - 'рубать'), переглядач вместо браузер в значении 'программа, предназначенная для просмотра сайтов, гипертекстовых документов в Интернете', этот вариант функционирует в соцсетях, 6 примеров найдено в корпусе ГРАК; для термина дисплей на сайте предложено и неосемантизм плесо, обозначающий водную гладь в общеупотребительной лексике, и новообразование висвітник. Последнее слово отсутствует в корпусах и словарях, возможно, это производное образовано по аналогии с польским wyświetlać. Вместо термина драйвер в значении 'компьютерная программа, с помощью которой операционная система получает доступ к прибору аппаратного обеспечения' предложен вариант розпізнавач. Это слово встречается в словарях на сайте $\mathrm{r} 2 \mathrm{u}$, в частности, в словаре Святослава Караванского, «Російсько-українському словнику складної лексики» (2012), но с другим значеним: 'той, хто розпізнає (душу, звук)' как перевод рус. различающий, распознающий. Таким образом, относительно перспектив вхождения новообразований в терминосистему информатику вырисовывается довольно пестрая картина: от принятия удачных вариантов (застосунок) до отсутствия их в текстах (висвітник).

\section{6. Окказионализмы}

Поскольку в статье рассматриваются не только новые производные, но и окказионализмы, необходим практический инструмент определения окказионального образования в массиве новой лексики. На основе приведенных выше признаков окказионализмов главным критерием их определения является нормативная маркированность - несоответствие словообразовательной норме. Дополнительным критерием служит маркер распространенности, употребительности лексической единицы в языковой практике (узусе), т.е. перспективы стать узуальной. Таким образом, претендент на статус окказионализма тестируется по критериям соответствия производного слова правилам словообразования и дополнительно по распространенности использования в языковой практике. Критерий распространенности в узусе имеет прежде всего практическую направленность оценки возможностей новообразований конкурировать с новыми английскими заимствованиями и войти в состав нормативного лексикона национального языка, что актуально в контексте процессов глобализации.

Таким образом, анализ каждого новообразования проводился по определенному алгоритму. Первый его шаг - проверка словообразовательной структуры нового слова на соответствие с существующей словообразовательной моделью (соответствует или образована с нарушением словообразовательного образца с прагматической целью (игровое, каламбурное, экспрессивно-оценочное)). Следующий шаг - верификация распространенности слова в узусе с помощью баз данных, корпусов, поисковых машин, предоставляющих также статистические данные об употреблении слова. Это важный фактор для понимания перспективы принятия авторского окказионализма языковым сообществом либо отсутствия его употребления вне конкретного контекста. Существенным также оказывается различие двух функциональных разновидностей окказионализмов: 1) стилистически нейтральные, созданные 
с целью назвать новое явление/объект; 2) эмоционально маркированные, созданные с целью авторской оценки, выражения отношения к определенному явлению/объекту.

Авторские окказиональные варианты заимствованных компьютерных терминов на сайте «Словотвір» принадлежат к стилистически нейтральным окказионализмам.

Вместо термина сканер (англ. scanner от scan - 'тщательно рассматривать, рассматривать') предложено Юрком Зеленым зняткувач, а Александром Страшко производные знятка сканированная страница, зняткування - сканирование.

Для заимствования спам (англ. spam - от spiced ham, то есть 'пряная ветчина'), обозначающего 'массовую рассылку корреспонденции рекламного или иного характера людям, которые не выразили желания ее получать', предложен вариант шкул, производное от глагола дошкуляти - донимать. Об этом примере, возникшем в английском языке вследствие терминизации лексики, а в языках-реципиентах, как украинский, утратившем внутреннюю форму, писала Н.Ф. Клименко (Клименко, 2017: 146). Спам адаптировался в языке вместе с целым словообразовательным гнездом (спамерський, антиспам, антиспамерський, спамити), поэтому у других претендентов нет никаких шансов уменьшить его активность.

На замену английскому термину драйвер - 'компьютерная программа, с помощью которой операционная система получает доступ к прибору аппаратного обеспечения’ - на сайте предложены варианты стиківник, долад, керун. Каждое из предложенных производных мотивированное слово, образованное с учетом дефиниции термина: долад - 'программа, созданная до ладу, т.е. для системы’ (в украинском языке лад также обозначает систему); стиківник - 'программа, которая стыкуется', керун - 'программа, которая руководит'. Но тем не менее ни один из предложенных окказионализмов не обнаружен ни в одном из электронных ресурсов, т.е. не вошел в употребление.

\section{7. Экран и его окказиональные производные}

Латинизм монітор (лат. monitor) в украинском языке в разные годы ХХ столетия функционировал с разными значениями, в одном из них сейчас он синонимичен англицизму дисплей (англ. display) (Клименко, 2017: 158-159). Давнее заимствование из французского екран (фр. écran - 'заслон, ширма') сохраняет более широкую семантику (поверхность, в т.ч. различных аппаратов), носители языка обычно различают слова екран (телевизора) и дисплей (компьютера). Сайт «Словотвір» предлагает заменить галлицизм екран украинским слона, являющимся буквальным переводом фр. écran. Слово оформлено без приставки в женском роде с ударением на последний слог слона́. К достоинствам предлагаемой инновации автор причисляет ее краткость и немотивированность, позволяющие увеличить ее словообразовательный потенциал: широкоекранний - широслонний. При этом, однако, не учтена омонимия с родительным падежом единственного числа существительного слон (кого? слона), что перечеркивает вышеперечисленные достоинства и перспективы узуализации этого новообразования.

Статистика употребления заимствования екран в текстах корпуса ГРАК - 13337 словоупотреблений на 1 млн также свидетельствует о его стабильном функционировании в украинской языковой практике. Его словообразовательный потенциал насчитывает десятки производных и все время возрастает, в том числе и за счет окказиональной лексики. Например, недавно изданная серия книг для детей А.Ю. Есаулова называется «Заекрання» 
(Заэкранье). Образован этот окказионализм со значением 'территория/пространство, находящиеся за чем-либо, отделяющим ее/его от остального (за рекой, за Карпатами, за зеркалом)' по словообразовательной конфиксальной модели: Заріччя, Закарпаття, Задзеркалля («Аліса в Задзеркаллі» Л. Керрола). Заекрання обозначает сказочную компьютерную страну, находящуюся за дисплеем (экраном) компьютера. Автор избрал производящей основой именно экран, а не дисплей или монитор. Верификация в корпусах, КФИ и Гугл показала, что и слово, и его производные: заекранський, заекранник, воїн-заекранник функционируют только в авторских художественных текстах. Относительное прилагательное заекранський образовано от Заекрання: долари заекранські 'деньги, принятые в Заэкранье' (Есаулов, 2013а: 4), заекранським ім'ям 'имя, принятое в Заэкранье' (ЕСАулов, 2013а: 32). Окказиональное название лица заекранник (ЕсАулов, 2013а: 8, 11) обозначает не жителя Заэкранья (тогда надо было бы использовать модель заекранець по аналогии с закарпатещь), а участника, «бойца» компьютерной игры, отсюда и воїн-заекранник (ЕСАУлов, 2013а: 13). Эта модель используется писателем в окказионализме иещеанець (житель планеты «Ц») (ЕСАулов, 2013с: 44). Таким образом окказионализмы Заекрання, заекранський, заекранник созданы писателем с целью номинации нового объекта в конкретном тексте и не имеют перспектив употребления вне данного контекста. Кстати, на сайте «Словотвір» есть предложение использовать слово заекрання вместо нового заимствования брендвойс - 'голос за кадром', но этот вариант не получил поддержки пользователей.

\section{8. Словообразовательный потенциал неосемантизма ицфровий}

Распространение современных цифровых технологий, получение и обработка информации в ицфровом формате (англ. digital data) с использованием цифровых технологий и ииифровых устройств (англ. digital device) стали источником нового семантического заимствования из английского языка изифровиц̆, в отличие от давнего заимствования иифра из арабского языка через латынь и французкий (фр. chiffre - 'число'). Попытки предложить украинский вариант числина вместо иифра на сайте «Словотвір» не могут увенчаться успехом, хотя слово и соответствует украинской словообразовательной модели. Но статистика употребления слова ицфра в текстах корпуса ГРАК - 9146 словоупотреблений на 1 миллион - свидетельствует о его стабильном функционировании в языке. Компьютерный фонд инноваций подтверждает также высокий синтагматический и словообразовательный потенциал прилагательного иифровий (англ. digital) в нескольких десятках примеров: иифровий декодер, запис, канал, носій; иифрове обладнання, телебачення; иифрова версія, мережа, модель; наличием новых производных оцифрувати, оцифруватися, оцифрування, иифровик (иифровий фотоапарат): «На „озброєнні” юних фотографів один звичайний „цифровик”...» (Хрещатик, № 66, 2006). В словаре «Словотворчество независимой Украины. 2012-2016» А. Нелюбы, Е. Редько находим пример окказионального словообразования: иифровізація в значении 'опредмеченное действие (процесс), связаннное с цифровыми технологиями’ (СНУ 2017: 436). В книге А. Есаулова «Game over!» использован глагол перецифрувати - «...тебе ми зараз перецифруємо на цьому перетворювачі» (ЕСАулов, 2013с: 91) и название лица цифбоєць (ЕСАулов, 2013с: 114), т.е. иифровий боєць - 'участник компьютерной игры'. Множество производных от производящей единицы в новом значении, связанном с передачей данных в цифровом формате, 
свидетельствует о стабилизации слова цифровий именно в новом терминологическом значении (иифровий сигнал - бітовий потік), хотя в общеупотребительных словарях это значение отсутствует.

\section{9. Конкуренция номинаций смайл - усміхайлик}

Смайл как элемент массовой культуры возник благодаря распространению сети Интернет в широких слоях населения. Среди попыток найти украинский вариант замены смайла (англ. smile - 'улыбка', укр. усмішка) - 'короткой знакограммы, отображающей эмоцию на письме', особой популярностью пользуется усміхайлик, зафиксированный и в словаре «Словотворчество независимой Украины. 2012-2016» А. Нелюбы, Е. Редько, и на сайте «Словотвір», и в единичном примере в корпусе ГРАК (текст из Фейсбука; для сравнения смайл в ГРАК имеет 110 словоупотреблений на 1 млн), а статистические данные поиска в Гугл дают более 32000 найденных единиц. Другие предложения на сайте «Словотвір» емоційка, почуттівка являются лексическими окказионализмами и более точно отображают его смысловую сущность - выражать различные эмоции, а не только улыбку, но пока остаются нераспространенными в узусе.

\section{0. Неологизмы и окказионализмы в интернет-коммуникации}

В проанализированных примерах окказионализмы исконного происхождения созданы преимущественно сознательно с целью номинации новых понятий и явлений средствами украинского языка. Однако существует большое число окказионализмов гибридного происхождения, в которых заимствованный термин (либо названия баз данных, соцсетей, поисковых систем) используется как производящая основа для образования окказиональных производных, в том числе и с целью выражения эмоциональной оценки. Например, кіберкак сокращенная основа прилагательного кібернетичний во многих сложных словах-новообразованиях (в словаре «Словотворчество независимой Украины. 2012-2016» А. Нелюбы, Е. Редько насчитывается 39 таких лексем) имеет прагматический ореол, например, названия операций по блокированию мобильных телефонов террористов, организованных активистами Кіберураган, Кібершторм или же ироническое название компьютера кіберящик по аналогии с телеящик. Названия соцсетей имеют также высокий словообразовательный потенциал, реализующийся и в окказиональной разговорной лексике. Это прежде всего зафиксированный в названном словаре целый спектр названий лиц - пользователей сетей, среди которых, например, Фейсбук: фейсбукец, фейсбуківець, фейсбучанин, фейсбучник, фейсбуківка, фейсбучка, и Инстаграмм: інстаграмівець и др. Значительная часть это гибридные глаголы, образованные по активным словообразовательным моделям, но с выразительным разговорным оттенком, лексические окказионализмы: перегуглити (избыточное действие: 'прогуглить больше, чем кто-либо'), оскопусити ('заставить писать статьи в издания, индексированные в наукометрической базе «Скопус»'), перефейсбучити (избыточное действие: 'писать в Фейсбуке больше, чем кто-либо'). Контексты дают ещё дополнительные эмоциональные коннотации, усиливающие окказиональность глаголов. 


\section{1. Выводы}

Проанализированный материал позволяет утверждать, что хотя лексика, принадлежащая к сфере информатики, преимущественно создается с целью номинирования новых объектов и явлений, попытки создания терминов-неологизмов на основании словообразовательных ресурсов украинского языка имеют переменный успех. Частично это связано с объективными моментами: краткостью номинации, отсутствием побочных значений или коннотаций, вхождением в язык сразу целым словообразовательным гнездом, т.е. высокий словообразовательный потенциал; частично с субъективным фактором «моды» или «привычки» пользователей. Благородная миссия создавать компьютерную терминологию на базе ресурсов только украинского языка сознательно направлена на сохранение и активизацию использования украинского языка в кибер- и интернетпространстве. Такое словотворчество носителей языка приводит к успеху, когда в номинацию включаются семантическое словообразование, явление «миграции» терминов, метафоризация лексики. Но в ряде случаев авторские предложения производных украинских лексем на роль терминов терпит фиаско. Это связано с отягощенностью значения слова другими значениями, если это неосемантизм, неспособностью производного образовать нужное словообразовательное гнездо терминов. Употребление новообразований ограничивают нежелательная омонимия, низкий или нулевой словообразовательный потенциал по сравнению со стабилизировавшимися заимствованиями, привязанность к контексту либо создание окказиональных единиц с целью выразить отношение или дать оценку тому или иному явлению.

\section{Словари}

АРСУН, 2013: КАРПІЛОВСьКА Є.А., КИСЛЮК Л.П., КЛИМЕНКО Н.Ф., КРИТСьКА В.І., ПУЗДИРЄВА Т.К., Романюк Ю.В., ред., КАРПІЛовсьКА Є.А., відП. ред.: Активні ресурси сучасної української номінації: Ідеографічний словник нової тексики. Київ.

ГС, 2011: КРИТсьКА В.І., НЕДОЗИм Т.І., ОрЛОва Л.В., ПузДИРєвА Т.К., РОМАНюК Ю.В., ред., КлИмеНКО Н.Ф., відп. ред.: Граматичний словник української літературної мови. Словозміна: Близько 140000 слів. Київ [Електронний ресурс, режим доступа: http://www.mova.info/; доступ: 19.12.2019].

СНУ, 2017: НелюбА А., РЕдько Э., ред., НЕлюбА А., заг. ред.: Словотворчість незалежної України. 20122016. Словник. Харків.

\section{Электронные ресурсы}

Архівна тексична картотека української мови [Електронний ресурс, режим доступа: http://mova.cf/; доступ: 19.12.2019].

Генеральний регіонально анотований корпус української мови (ГРАК). ШведовА М., фон ВАльденФЕЛьс Р., Яригін С., Крук М., Рисін А., СтАрко В., Возняк М., Київ, Осло, Єна, 2017-2019 [Електронний ресурс, режим доступа: uacorpus.org; доступ: 19.12.2019].

Корпус української мови [Електронний ресурс, http://www.mova.info/corpus.aspx?11=209; доступ: 19.12.2019].

КФІ: Науково-дослідницький комп'ютерний фонд інновацій. 
Морфемно-словотвірний фонд української мови.

Російсько-українські словники [Електронний ресурс, режим доступу: http://r2u.org.ua/; доступ: 19.12.2019].

Словотвір [Електронний ресурс, режим доступу: https://slovotvir.org.ua/; доступ: 19.12.2019].

\section{Литература}

БулАховський К.А., 2010: Стан і проблеми розвитку україномовної локалізації компютютених програм. „Українська мова”, № 4, с. 89-94.

ЕСАУЛОВ О.Ю., 2013а: «Game over!». Харків.

ЕСаулов О.Ю., 2013b: Антивірус. Харків.

ЕСаулов О.Ю., 2013с: Таємниия великого Сканера. Харків.

КАРПІловська Є.А., 2008: Тенденцї̈ оновлення сучасного українського тексикону. В: Клименко Н.Ф., відп. ред.: Динамічні проиеси в сучасному українському тексиконі. Київ, с. 6-133.

Клименко Н.Ф., 2017: Процеси розвитку терміносистеми інформатики. В: КАРПповсьКА Є.А., відп. ред.: Вплив суспільних змін на розвиток української мови. Київ, с. 122-183.

Колоїз Ж.В., 2007: Українська оказіональна деривація: монограбія. Київ.

ПуСтовіт Л.О., КлименКО Н.Ф., 2004: ОКазіоналізМ. В: РУСАНІвСьКИЙ В.М., ТАРАНЕНкО О.О., співгоЛ. редкол.: Українська мова: Енциклопедія. Київ, 2-е вид., с. 432-433.

СТАРКо В.Ф., 2017: Комп'ютерні лінгвістичні проекти гурту г2и: стан та застосування. „Українська мова", № 3, с. 86-100.

Янко-триницКАЯ Н.А., 2001: Окказиональное словообразование. В: Той ЖЕ: Словообразование в современном русском языке. Москва, с. 462-482.

Belentschiкоw R., 2003: Неузуальное словообразование: Восточнославянские языки. W: ОhNнeiser I., red. nauk.: Stowotwórstwo / Nominacja. Innsbruck, Opole, s. 249-261.

Buzassyova K., Martincova O., 2003: Neuzualni slovotvorba v zapadoslovanskych jazycich. W: OhNHeiser I., red. nauk.: Stowotwórstwo / Nominacja. Innsbruck, Opole, s. 262-275.

CHRuścińsKA K., 1978: O formacjach potencjalnych i okazjonalizmach. W: SZYMCZAK M., red.: Z zagadnień słownictwa wspótczesnego języka polskiego. Wrocław-Warszawa-Kraków-Gdańsk, s. 69-79.

JADACKA H., 2001: System stowotwórczy polszczyzny (1945-2000). Warszawa.

JóźwIKIEWICZ P., 2011: Ukraińska terminologia informatyczna: stan, problemy, zapożyczenia. „Slavica Wratislaviensia”, nr 154, s. 121-132.

JóźwıKıewicz P., 2014: Ukraińskie słowniki terminologii informatycznej (1990-2010). „Slavica Wratislaviensia” CLIX, Acta Universitatis Wratislaviensis, nr 3578, s. 179-188. 